\title{
Golden5: uma proposta de construção de um bom ambiente de aprendizagem
}

Golden5: a proposed construction of a good learning environment

Rita de Cássia de Souza*

Universidade Federal de Viçosa

Maria Jose Lera Rodriguez**

Universidad de Sevilla

Resumo O Programa de intervenção educativa Golden5, foi criado em 2004 por uma equipe internacional visando melhorar o clima escolar no ensino secundário que passava por dificuldades semelhantes em vários países. Atualmente, seu uso tem se estendido para escolas infantis, primárias e atividades extraescolares para alunos com dificuldades escolares. Seu objetivo é melhorar o ambiente escolar a partir da intervenção docente. Para tanto, oferece aos professores um conjunto de ferramentas e habilidades que auxiliam a compreender o funcionamento do grupo e geri-lo de forma mais adequada. Vários estudos realizados acerca da aplicação do Golden5 em vários países, incluindo avaliações internas e externas ao Programa, mostraram resultados muito positivos. Apesar disso, é preciso considerar que sua aplicação depende da motivação e eficiência dos professores e isso certamente interfere nos resultados.

PALAVRAS-ChaVE: Educação, Clima escolar, Golden5.

Abstract The educational intervention Golden5 Program was created in 2004 by an international team to improve the school environment in secondary education by passing similar difficulties in several countries. Currently, its use has been extended to preschools, primary and extracurricular activities for students with learning difficulties. The Golden5 aims to improve the school environment and its effectiveness from the teacher intervention. Therefore, offers teachers a set of tools and skills that help to understand the functioning of the group and manage it more adequately. Several studies on the implementation of Golden5 in several countries, including internal and external evaluations of the Program, showed very positive results. Nevertheless, one must consider that the application of Golden5 depends on motivation and efficiency of teachers and that certainly affects the results.

KEYWORDS: Education, School environment, Golden5. 


\title{
Introdução
}

Este artigo tem por objetivo apresentar o Programa Golden5 ${ }^{1}$, os resultados obtidos nos países em que foi aplicado ${ }^{2}$ e as possibilidades de sua aplicação no Brasil. O Programa teve início com um Projeto em $2004^{3}$, criado por um grupo de seis professores de cinco países da Europa ${ }^{4}$, a partir da necessidade de melhorar o clima escolar no ensino secundário que passava por dificuldades semelhantes em vários países:

\begin{abstract}
A situação atual na Europa, relativa à educação em geral, e especialmente na educação secundária parece ser bastante similar. Em geral, todos os países da comunidade enfrentam desafios semelhantes, como é dar resposta às necessidades da sociedade atual, com mais diversidade intercultural, religiosidade, social, etc., o que cria grupos mais heterogéneos nos quais as fórmulas tradicionais simplesmente não funcionam.
\end{abstract}

Os cinco países envolvidos neste projeto têm problemas semelhantes nas suas escolas, e, todos relacionados com o comportamento dos alunos e as suas consequências, especialmente no baixo nível de desempenho dos alunos em risco de exclusão social. (LERA, 2009, s.p.)

$\mathrm{Na}$ escola secundária, os estudantes tendem a ter menos motivação nos estudos e mais conflitos (ESTRELA, 1992; DEL REY, ORTEGA, 2003). No entanto, a aplicação do Golden5 pode ser bem mais ampla. Atualmente, o Golden5 tem sido aplicado em escolas infantis, primárias e em atividades extraescolares para alunos com dificuldades escolares. Está sendo desenvolvido também em alguns territórios da Palestina, o que demonstra que pode ser adequado a outras realidades.

Os números da educação, no Brasil, cresceram muito nas últimas décadas, no entanto, o rendimento escolar dos estudantes não tem sido proporcional (IPEA, 2006). Muitos estudos destacam os problemas em relação à convivência nas escolas brasileiras, como a violência, incluindo o bullying (MALTA et al, 2010; GONÇALVES e TOSTA, 2008; PUPO, 2007; GOMES, 2006; FANTE, 2005; ABRAMOVAY et al, 2005, 2002; ABRAMOVAY e CASTRO, 2003; GONÇALVES e SPOSITO, 2002; VIEIRA, MENDES e GUIMARÃES, 2009; FRANCISCO e LIBÓRIO, 2009; SPOSITO, 2001) e a indisciplina (AQUINO, 2011; VASCONCELOS, 2006; LA TAILLE, PEDRO-SILVA e JUSTO, 2006).

Há pesquisas que apontam a existência de uma correlação positiva entre rendimento e bom clima escolar (GOMES, 2005; CASASSUS 2002; ABRAMOVAY, 2003) que são justamente os principais objetivos do Golden5: melhorar o ambiente escolar e sua efetividade. O Golden5 é direcionado aos professores e, apesar da complexidade dos fatores que interferem na aprendizagem e na criação de um bom clima escolar, trata-se de um projeto simples, de fácil aplicação e que torna os professores investigadores de sua própria realidade, oferecendo ferramentas para que construam seus próprios caminhos. "Efectivamente, solo con una actitud investigadora y un espíritu crítico ante la realidad y las propias opiniones, es posible enfrentarse a los fenómenos de conflictividad actualmente presentes en las aulas y en los contextos educativos. (DEL REY; ORTEGA, 2003, p. 26) 
Embora tenha os professores como protagonistas neste processo, o Golden5 propõe a criação de grupos de apoio, entre os pares, junto às famílias dos alunos e à comunidade, pois "[...] con frecuencia se tiende a olvidar que en el proceso de educación, aculturación o socialización de los individuos y los grupos, la escuela no es la única institución que interviene y, a menudo, ni siquiera es la más influyente. (HERNÁNDEZ Y HERNÁNDEZ; GIL, 2004, p. 13)

$\mathrm{E} 1$ proyecto Golden5 tiene como objetivo crear [...] un programa educativo dirigido al profesorado que le ayude a tener un ambiente escolar más agradable y efectivo en el aula. Este proyecto está fundamentado en la creencia de que las escuelas tienen importantes responsabilidades en la educación de los futuros ciudadanos y en el desarrollo de actitudes saludables hacia ellos mismos, los otros y la sociedad, teniendo especialmente en cuenta que los niños en riesgo de exclusión social necesitan una atención especial. Los docentes necesitan ser competentes dirigiendo estrategias y mejorando el desarrollo social de los niños y niñas, y de las clases como un grupo. En este sentido, el programa Golden5 propone un principio, unas áreas y unos pasos claves que ayudan a conseguirlo.(LERA, 2009, s.p.)

A palavra em inglês golden significa dourado, algo que é precioso, importante, excelente. É justamente este o propósito do Golden5: fazer brilhar a todos e a cada um, potencializando o melhor dos envolvidos, sejam estes educadores ou estudantes. $\mathrm{O}$ número 5 é uma referência que visa facilitar o trabalho dos docentes, pois todas as atividades desenvolvidas giram em torno de 5 . Se o educador tiver muitas atividades para desenvolver pode não ter tempo, ou ficar sobrecarregado, fazendo 1 ou 2 apenas, e pode não visualizar nenhum resultado. Por isso, o número 5 foi identificado como sendo ideal para este trabalho.

O Golden5 está baseado na teoria atribucional e do equilíbrio de $\mathrm{Heider}^{5}$ que buscava compreender a relação entre motivação e atribuições causais.

Este autor propunha que nossas ações derivam de causalidade pessoal ou impessoal. A primeira depende do controle do indivíduo. A segunda está subordinada às forças externas, ao ambiente. Se percebemos uma ação como derivada de forças pessoais, estamos fazendo uma atribuição de causalidade pessoal. Se atribuímos o evento a forças externas às pessoas, sobre as quais elas não têm controle, estamos fazendo uma atribuição de causalidade impessoal. (BECK, 2001, s.p.)

Quando aplicada à educação, pode-se afirmar que, se o estudante estabelece relação entre seu esforço, e os bons resultados obtidos tende a se motivar. No entanto, se considera que os resultados obtidos dependem de fatores externos, como sorte ou boa vontade do professor, tenderá a se esforçar menos para obter bons resultados.

De acordo com a teoria do equilíbrio, também formulada por Heider (1958):

[...] as pessoas tendem a manter sentimentos e cognições coerentes sobre um mesmo objeto ou pessoa, de modo a obter uma situação de equilíbrio. Quando esse equilíbrio se desfaz, elas vivenciam uma situação de tensão e procuram restabelecê-lo, mediante a mudança de algum dos elementos da situação. Tal princípio encontra-se na 
base das teorias da consistência cognitiva que irão proliferar nos anos seguintes. (FERREIRA, 2010, p.2-3)

Influenciado por estes trabalhos, Newcomb (1961) desenvolveu a "teoria A-B-X". Aplicadas ao contexto escolar, estas teorias apontam que a opinião compartilhada pelos sujeitos reforça e fortalece os laços de união entre eles e os que possuem opiniões distintas sobre um assunto tendem a um afastamento. Como as pessoas buscam aproximação, a opinião de uma influencia outras. Isso significa que o que um professor fala acerca de um estudante pode se tornar uma opinião compartilhada mesmo que outros professores não tenham a mesma experiência. Assim também os estudantes em relação a seus professores, a seus colegas, etc. As afirmações dos professores costumam ser muito significativas na escola, seja entre seus pares ou entre seus alunos, podendo influenciar bastante a opinião dos demais.

As pessoas costumam selecionar, da realidade, elementos que corroborem suas crenças e expectativas e podem influenciar inclusive a auto-percepção e autoconceito dos demais. Rosenthal e Jacobson (1968) realizaram um estudo em escolas públicas elementares nos Estados Unidos, no qual aplicavam um suposto teste aos estudantes e, ao final, comunicavam aos professores quais alunos foram melhor e quais pior. No entanto, a classificação dos estudantes foi aleatória, pois o teste sequer existia. Mesmo assim, os professores acreditaram que as capacidades dos estudantes eram diferentes e isso influenciou o resultado destes ao final do ano. Eles concluíram que as expectativas dos professores influenciam os resultados dos alunos, ou seja, alunos cujos professores tinham expectativas mais altas tinham rendimento mais alto e aqueles cujo se esperava baixos resultados, assim o fizeram. Este fenômeno foi denominado Efeito Pigmaleão ou Profecia auto-realizadora.

De acordo com um estudo feito por Harter (1996), a autoestima dos estudantes na pré-adolescência e adolescência é influenciada, em primeiro lugar, pelos iguais e, em segundo, pelos pais, em terceiro, pelos professores e, finalmente, pelas amizades mais íntimas. Esta pesquisa revela que, mesmo não tendo o mesmo peso dos iguais, pais e professores também influenciam o autoconceito dos adolescentes e devem estar atentos a isso. Também é possível que percepções positivas dos professores, em relação aos estudantes, possam compensar atribuições negativas dos demais.

Bru, Stephens e Torsheim (2002) afirmam que relações positivas entre professores e alunos reduzem problemas de comportamento em aula e aumentam o nível de concentração acadêmica dos estudantes. Birch e Ladd (1996) propuseram 3 características na relação professor-aluno as quais são importantes especialmente para crianças menores: proximidade, dependência e conflitos. Uma boa relação tende a aumentar a proximidade, diminuir a dependência e os conflitos. 
Wentzel (1996), solicitou aos estudantes que escrevessem 3 coisas que os professores faziam capazes de indicar que eles se importavam com os alunos, e 3 que indicavam o contrário. As respostas foram categorizadas em 4 dimensões:

Quadro I: Comportamento dos professores que se importavam ou não com os alunos

\begin{tabular}{|c|c|}
\hline Comportamento dos que se importavam & $\begin{array}{c}\text { Comportamento dos que não se } \\
\text { importavam }\end{array}$ \\
\hline Tinham relações democráticas & $\begin{array}{c}\text { Tinham relaçoses autoritárias e com falta de } \\
\text { respeito }\end{array}$ \\
\hline $\begin{array}{c}\text { Reconheciam as diferenças individuais } \\
\text { (sociais e acadêmicas) }\end{array}$ & Tratavam os alunos por igual \\
\hline Tinham altas expectativas de sucesso & Esperavam resultados baixos \\
\hline $\begin{array}{c}\text { Encorajavam positivamente e recebiam } \\
\text { feedback }\end{array}$ & $\begin{array}{c}\text { Apregoavam a baixa capacidade dos } \\
\text { estudantes }\end{array}$ \\
\hline
\end{tabular}

Fonte: Quadro baseado nos estudos de Wentzel (1996)

A pesquisa mostra o quanto o comportamento dos professores pode alterar suas relações com os alunos, pois aqueles que apresentavam comportamentos de que não se importavam com os alunos tinham relações mais conflitivas com eles. Além disso, Wentzel mostrou que também, quanto mais os estudantes possuem comportamentos pró-sociais ou de responsabilidade social, mais tendem a ser ajustados na escola. Isto mostra o quanto o efeito do grupo é importante.

Num dos primeiros estudos de Psicologia Social, Norman Triplett (1898) chamou de "efeito de coação" o fato das pessoas tenderem a aumentar seu rendimento ao realizarem atividades em conjunto. $\mathrm{O}$ trabalho em grupo, na perspectiva do Golden5, não visa a concorrência, pois o propósito é sempre inclusivo e de cooperação, mas considera que o trabalho coletivo pode ser muito mais estimulante que o individual.

Cottrell et al (1968) afirmam que há mudança no rendimento quando a pessoa sabe que seu comportamento está sendo observado, podendo gerar um resultado melhor ou pior, dependendo da expectativa existente. Se as expectativas são altas, a tendência é de uma maior motivação e dedicação e, consequentemente, isso influi para que se tenha um bom resultado, por outro lado, se a expectativa não é grande, a motivação e a dedicação também diminuem e os resultados tendem a ser mais baixos. A esse fenômeno chamou-se "efeito audiência".

\section{Características do Programa Golden5}

Baseando-se nestas teorias, o Golden5 propõe a formação dos professores conforme um conjunto apropriado de ferramentas e habilidades para compreender o funcionamento do grupo e gerí-lo de forma mais adequada. Tendo os educadores como protagonistas do processo, o Golden5 inicia com a sensibilização. Antes de tudo, é preciso acreditar na possibilidade da mudança e ter desejo de realizá-la. Por isso, a participação da escola e dos professores é voluntária, livre e não envolve nenhum tipo de obrigatoriedade. 


\begin{abstract}
Desde este modelo se defiende que sólo cuando los comportamientos (las acciones) están basadas en una necesidad de hacer algo, en unos sentimientos (sensibilización) y un conocimiento profundo del problema (formación), tienen consecuencias externas y mejoran la situación. Es interesante recordar que este modelo procede de la educación para el desarrollo y es utilizado para valorar las acciones que se ponen en marcha para la mejora del llamado Tercer Mundo o países en vías de desarrollo. Entienden que cuando las acciones vienen motivadas sólo por una sensibilización suelen ser desajustadas, no se mantienen en el tiempo, y en muchos casos no sirven para realmente paliar el problema social que está tratando. (LERA, s.d., p. 6)
\end{abstract}

Para ser Golden5, há um processo de formação e acompanhamento para a aquisição dos princípios básicos. No entanto, como o programa está disponível na internet e é aberto a todos, o interessado pode se informar na página de como desenvolver o trabalho e buscar ajuda nos fóruns de discussão. Se os professores de uma escola atuarem em conjunto na aplicação do Golden5 terão melhores resultados. Nada impede que um professor atue sozinho, mas sua influência será pequena. Algumas reuniões devem ser pensadas para intercâmbio de experiências e apoio. No caso da formação, são previstas reuniões com o grupo formador para esclarecimento de dúvidas e motivação.

Las competencias Golden comparten un principio común que predispone al sujeto a actuar de determinada manera. Este principio común es para nosotros la "positive approach", o que hemos calificado como "principio Golden", que comparte que todo tiene una perspectiva positiva que hay que intentar destacar, desde la enseñanza hasta uno mismo. [...]Este principio toma aún más importancia cuando se hace explicito, y especialmente cuando se potencia en grupo. En este caso las teorías de la atribución social y del efecto audiencia explican el efecto multiplicador de ser percibido como "golden". Es decir, parte de la importancia de considerar una perspectiva positiva hacia el alumnado, por sus implicaciones en su desarrollo personal, y por la eficacia de esta perspectiva cuando se realiza en grupo, y el aula es un grupo social. Desde esta perspectiva teórica se intenta crear las mejores expectativas en el alumnado, incluyendo toda la diversidad e individualidad del grupo. (LERA, 2009d)

Dada a complexidade dos fatores que atravessam o processo de aprendizagem e das relações interpessoais na escola, o Programa Golden5 estabelece 5 áreas básicas. Considera-se que, atuando nelas, já é possível obter alguns resultados. Uma intervenção muito limitada pode não ser significativa, uma muito ampla pode não ser viável. As áreas básicas Golden5 são: 1) Gestão de aula; 2) Construindo relações; 3) Clima Social; 4) Aprendizagem ajustada e 5) Relações família-escola.

O educador pode começar a aplicação do processo desde o conhecimento da primeira área. É um processo gradual, de observação e experimentação que pode ser vivenciado de forma diferente por cada aplicador. Trata-se de uma proposta flexível pois as ferramentas são oferecidas e cada um escolhe como utilizá-las. Há algumas sugestões básicas, mas boa parte do processo é construído pelo próprio professor. Para começar a aplicação, são importantes as seguintes fases: 
1. Autoavaliação do professorado que consiste em conhecer cada realidade com suas especificidades. Como forma de sensibilizar os professores a conhecerem a sua realidade, há um questionário para cada área Golden5 que pode ser preenchido pelo próprio professor; o questionário "Eu e a Escola" para ser preenchido pelos alunos e a proposta de um sociograma que auxilia o professor a entender as relações estabelecidas em classe pelos estudantes. ${ }^{6}$

2. Seleção de 5 ou 6 passos chaves de uma, duas ou quantas áreas Golden 5 o educador escolher. Existem vários passos chaves disponíveis, e cada um escolhe os que lhe parecemmelhores.

3. Seleção de 5 estudantes Golden 5 para uma aplicação mais sistemática de alguns passos. Deve-se trabalhar com um grupo de 5 estudantes por um período de 5 dias e avaliar os resultados. É fundamental que este grupo de estudantes seja o mais heterogêneo possível. Se o professor trabalhar sempre com um grupo conhecido como participativo, apático, indisciplinado, etc., logo criará suspeitas nos alunos. A heterogeneidade permite observar como diferentes estudantes respondem às estratégias utilizadas. Estes estudantes precisam ser trocados a cada 5 dias pois todos os alunos devem ter seu momento Golden5. O professor precisa registrar e acompanhar sistematicamente quem são os alunos Golden5 da semana para não enfatizar uns e esquecer outros.

4. Aplicação dos passos chaves e anotação do que foi feito e dos resultados obtidos. Os 5 passos chaves escolhidos devem ser aplicados durante 5 dias em cada turma $^{7}$. A aplicação dos passos é importante, mas o resultado depende da sistematicidade do processo. Para isso, o professor precisa controlar o que fez e os resultados de seu trabalho. Pode usar uma folha de avaliação em que registra suas próprias observações acerca desta experiência. Feito isso, avalia e escolhe os passos chaves da próxima semana. Estes podem ser os mesmos da semana anterior, ser completamente diferentes ou mesclar novos e outros já utilizados.

5. Comprovando resultados. O processo inicia e finaliza com uma autoavaliação. Deve-se analisar o que deu certo, o que precisa ser melhorado e, a partir daí, reiniciar o processo. $\mathrm{O}$ Golden5 não se propõe como uma alternativa passageira e emergencial. Aqueles que o experimentam e confirmem seus resultados devem seguir utilizando e compartilhando suas experiências com outros educadores.

A atuação do Golden5 é pensada para educadores, realizada e avaliada por estes. Sua aplicação exige que os educadores tenham uma consciência crítica e reflexiva do seu fazer cotidiano. Para obter resultados na aplicação do Golden5, é importante que o professor seja capaz de desenvolvê-lo de forma sistemática e consciente, analisando seus resultados para cada classe e cada contexto. Ele próprio deve escolher quando utilizar cada ferramenta. Não se trata de uma receita pronta. Tratam-se de novos modos de fazer que devem ser adaptados e remodelados segundo as necessidades de cada realidade.

O ideal é que os professores usem o Golden5 de maneira sistemática, analisando e discutindo seus resultados. $\mathrm{O}$ Golden 5 parte do princípio que as pessoas são diferentes e tem diferentes formas de aprender, desenvolver e que não se pode esperar o mesmo de todos. O papel do educador é facilitar a todos a construção de seus próprios caminhos. Consiste em facilitar para felicitar.

Para uma análise dos resultados mais efetiva, sugere-se que a aplicação do Golden 5 se dê por cerca de 3 meses, mas é possível ver os resultados a cada semana, a partir da autoavaliação dos educadores e também utilizando-se novamente o ques- 
tionário "Eu e a Escola" para averiguar a percepção dos estudantes. Espera-se que a aplicação do Golden5 promova um aumento da autoestima de estudantes e professores, aumento do rendimento escolar, diminuição dos conflitos, maior ajuste escolar e motivação.

Todas as informações necessárias para o trabalho estão na página www. golden5.org em espanhol, inglês, italiano, polonês, norueguês e árabe. O material de orientação para o Golden 5 foi traduzido para o português, entretanto, não está na página ${ }^{8}$. Podem ser encontrados vídeos, textos, questionários, propostas para salas de aula e fóruns de discussão sobre o Golden5 no Facebook, no twitter (@Golden5Project) e também no http://www.youtube.com/user/Golden5Project.

\section{Algumas análises sobre resultados do Programa Golden5}

Com o objetivo de ter uma avaliação do impacto causado pelo desenvolvimento do Golden5, em 2006, foi feita uma pesquisa9 ${ }^{9}$ (LERA et al, 2009a) envolvendo 15 escolas e 43 professores de quatro países participantes (Espanha, Itália, Polônia e Noruega). Os resultados mostraram que o Golden5 teve efeitos positivos sobre os estudantes, especialmente aqueles com maior risco de exclusão social. As mudanças dos professores foram perceptíveis em todos os países participantes.

Também, em 2007, foi feito um estudo piloto sobre o Golden $5^{10}$ com doze professores do ensino secundário da Espanha, Itália, Noruega e Polônia que participaram do Projeto (LERA et al, 2009). Os resultados mostraram que os professores usavam com facilidade os passos chaves propostos, professores e alunos sentiam-se mais satisfeitos em sala de aula, o ajuste escolar dos estudantes melhorou, sobretudo em relação ao sucesso acadêmico e social, e aumentou a motivação dos alunos. Embora os resultados dos trabalhos desenvolvidos sejam otimistas, é preciso considerar que, além das variações culturais, sociais, econômicas e políticas que interferem na educação de cada país, a aplicação do Golden5 depende da motivação e eficiência dos professores e isso certamente interfere nos resultados obtidos.

A primeira aplicação do Golden5, na Palestina ${ }^{11}$ envolveu vinte professores que atendiam cerca de 900 estudantes em Gaza e Hebron. Após a formação e desenvolvimento do Programa, foi aplicado um questionário aos professores, concebido para medir o impacto da formação e a eficácia do Programa, apontou resultados muito positivos. Por exemplo, quando perguntados se "a formação havia cumprido as suasnecessidadesna sua área detrabalho" $40 \%$ responderamcomum 10 e 20\%, comum 9 (que eram as notas mais altas) ${ }^{12}$ (LERA et al, 2009c).

Realizou-se ainda uma avaliação externa ${ }^{13}$ do Golden5 e uma das conclusões do trabalho foi:

El proyecto Golden resulta indicado para aquellos centros y profesores dispuestos afacilitar el éxito escolar de los alumnos con dificultades en su rendimiento académicopor razones de sus características personales, sociales o culturas.La aplicación adecuada del Programa Golden puede mejorar la convivencia en loscentros y en las aulas, además de aumentar el nivel de éxito escolar (aunque esteaspecto puede depender de otros factores no controlables por los participantes en elProyecto), especialmente los diseños curriculares y las normas de escolarización.(MOYA, 2007,p.12) 
De acordocom o avaliador externo:

Cualquier alumno o alumna puede ser beneficiario del Proyecto Golden ya sea de forma individual como de forma grupal y tanto en la etapa Primaria como Secundaria. No obstante, conviene señalar, que los principales destinatarios del Proyecto son los alumnos amenazados de exclusión social y que presentan dificultades en el aprendizaje. (MOYA, 2007, p. 11)

Dominguez et al (s.d.) recomendam aos professores a utilização do Golden5 para lidar com alunos com transtorno negativo desafiante e transtorno social. ${ }^{14}$ Em 2012 o Golden5 foi desenvolvido junto a professores de escolas públicas de $\mathrm{Se}$ vilha e também educadores de projetos sociais, totalizando 55 pessoas. ${ }^{15}$ Foram feitas 125 visitas às instituições para acompanhamento dos trabalhos. Além disso, foram distribuídas agendas aos participantes, nas quais anotavam os passos chaves e estudantes Golden 5 a serem destacados diariamente e, ao final de uma semana, pedia-se que estes respondessem às seguintes questões com respostas abertas sobre o trabalho com o Golden5: 1) Você considera que se saiu bem?; 2) Por que você considera que se saiu bem?; 3) Alguma coisa não saiu bem?; 4) Por que você acha que isto não saiu bem?; 5) No que você acha que deve se concentrar na próxima semana? Apenas 24\% do grupo devolveu a agenda preenchida. Foi pedido, ainda, que marcassem na agenda um grau de satisfação global semanal que se situou na média de 2,65 podendo se interpretar que eles se mostraram satisfeitos, mas não completamente. Havia ainda um espaço para outros comentários.

E1 100\% de los comentarios citaban la palabra "consciencia y/o reflexión”, describiendo que son más conscientes, que ven las dificultades y que las superan. Hay una reflexión sobre su práctica educativa y las consecuencias de las "pequeñas cosas" en el bienestar de los niños. Ej: "Golden en su globalidad es casi un cambio de actitud existencial, no tan radical, un cambio de óptica en la forma de contemplar la información". ${ }^{16}$

As maiores dificuldades citadas pelo grupo foram em relação à mudança de hábitos e de padrões de respostas, o fato de trabalhar sozinho (sem outros companheiros Golden5 para dividir as experiências). Quanto ao impacto entre os alunos, algumas respostas foram: "Se respira en el grupo un ambiente más sano, clima más tranquilo y positivo"; "Observo tranquilidad en mis alumnxs y estoy pendiente de sus necesidades"; "Las estrategias Golden tienen un rápido efecto a corto plazo, pero con problemas de conducta funciona a largo plazo". Além das avaliações internas ao Golden5, neste caso, foi aplicado um teste ${ }^{17}$ a 149 estudantes antes e após o Golden 5 com um intervalo de 8 a 10 semanas. Foram constatadas melhoras nas habilidades sociais, assim como melhora do rendimento académico tanto em primária quanto em secundária. Todas estas melhoras foram estatisticamente significativas.

Para analisar o período posterior a 2007, buscamos informações postadas nos fóruns de discussão do tema no site Golden5.org criado em 2007 e no facebook, cuja página foi aberta em março de 2011. No site foram encontradas 76 mensagens no fórum de discussões. Infelizmente, não houve muito intercâmbio e a maior parte das mensagens não foi respondida. Mesmo assim, seguimos nos interessando pelo conteúdo destas mensagens.Foram localizadas 75 mensagens, todas da Espanha ${ }^{18}$. Quase a 
totalidade é de professores da educação infantil, primária e secundária. Algumas mensagens são de um grupo ou de duas pessoas que escreveram juntas. Alguns informaram estar fazendo a formação Golden5 ou um curso sobre conflitos escolares. Outros tiveram acesso à página sem ter passado por um curso de formação. As mensagens do fórum não dão muitas pistas acerca do processo de aplicação do Golden. Poucas mensagens trataram do tema. Boa parte mostra-se muito entusiasmada, mas estão no início do processo e três mensagens chamaram a atenção ao afirmar que não tinham tempo, como professores, para aplicar o Golden5. Embora a aplicação dos passos chave em classe não demande disponibilidade de tempo do professorado, o registro das atividades, que é fundamental para a sistematicidade do trabalho e a autoavaliação ao final do processo (em torno de uma semana), são necessários para que os docentes possam analisar, refletir e avaliar suas próprias práticas.

A maior parte das mensagens, infelizmente, não passa de uma apresentação e busca de informações. É possível ver que a troca de experiências foi pequena. Um dos motivos pode ser a dificuldade de uso do próprio site. Alguns informavam que estavam aprendendo como usá-lo, e inclusive enviavam suas mensagens através de outras pessoas. Nem sempre, nestes cinco anos de uso, foi possível manter um moderador constante para responder as mensagens. Um dos grandes desafios do Golden5 é a continuidade. Os professores iniciam motivados e com esperança e, aos poucos, se não tem um grupo para discutir e se manter no processo, acabam por deixar de lado as atividades. Mesmo que alguns passos chaves sejam aplicados, é importante a sistematicidade do processo para que os resultados sejam visíveis.

O canal do Golden 5 no youtube foi aberto em 15 de março de 2011 e tem palestras em espanhol explicando o Programa. Na data da pesquisa, 18 de outubro de 2012, constavam 165 exibições. No facebook, não foi possível saber quantos são os usuários da página Golden5, 251 pessoas haviam curtido a página e há comentários de pessoas de Espanha, Bruxelas e Palestina na pesquisa de 18 de outubro de 2012. Dentre os vídeos publicados na página, há comentários e compartilhamentos, o que demonstra que a página tem sido utilizada.

\section{Considerações finais}

Obviamente o Golden5 não traz a solução para todos os problemas relacionados com a construção de um bom ambiente de aprendizagem. Aspectos relacionados a problemas sociais, econômicos, culturais, familiares não são diretamente abordados pelo Golden5. Trata-se de um Programa de fácil execução que possibilita ao professorado atuar dentro de seu âmbito de trabalho: estudantes, companheiros de trabalho e familiares dos estudantes. Não lhe exige que tenha horários extraescolares, a não ser alguns minutos na semana para reflexão de sua prática Golden5 e planejamento da próxima semana. Tudo é feito de forma a simplificar e facilitar o trabalho docente. Pode se afirmar que, dentro do seu âmbito de ação, os resultados do Golden5 são muito favoráveis, o que não exclui a necessidade de outros tipos de intervenção na escola, como projetos antiviolência, anti bullying, de mediação de conflitos entre outros, que sejam preventivos e não exclusivamente punitivos. Deve se considerar, no entanto, que são incompatíveis com o Golden5 projetos que compreendam a diversidade como desvio, anormalidade ou déficit (MOYA, 2007) e que tenham princípios competitivos e excludentes. 


\section{Referências}

ABRAMOVAY, M; CASTRO, M.G. Ensino Médio: múltiplas vozes. Brasília: UNESCO, MEC, 2003.

ABRAMOVAY, M (coord). Escolas inovadoras: experiências bem-sucedidas em escolas públicas. Brasília: UNESCO, 2003.

ABRAMOVAY, M. et al. Violências nas escolas. Brasília: UNESCO Brasil, REDE PITÁGORAS, Coordenação DST/AIDS do Ministério da Saúde, Secretaria de Estado dos Direitos Humanos do Ministério da Justiça, CNPq, Instituto Ayrton Senna, UNAIDS, Banco Mundial, USAID, Fundação Ford, CONSED, UNDIME, 2002.

ABRAMOVAY, M.et al. Cotidiano das escolas: entre violências. Brasília: UNESCO. Observatório de violência nas escolas. Ministério da Educação, 2005.

AQUINO, J. G. Da (contra)normatividade do cotidiano escolar: problematizando discursos sobre a indisciplina discente. Cadernos de Pesquisa. São Paulo, vol.41, n.143, p.456-484, ago. 2011.

BECK, M. L. G. A Teoria da Atribuição e sua relação com a educação. Revista Acadêmica Multidisciplinar. Maringá, ano I, n. 03, dez. 2001. Disponível em: <http://www.urutagua.uem. br//03beck.htm> Acesso em 17 out. 2012.

BIRCH, S.; LADD, G. Interpersonal relationship in the school environment and children's early school adjustment: the role of teachers and peers. In: JUNOVEN; WENTZEL. Social motivation: understanding children's school adjustment Cambridge: Cambridge University Press, 1996

BRU, E; STEPHENS, P.TORSHEIM, T. Students' perceptions of class management and reports of their own misbehavior. Journal of School Psychology, 40, n.4, p. 287-307, 2002.

CASASSUS, J. A escola e a desigualdade. Brasília, DF: Plano, 2002.

COTTRELL, et al. Social facilitation of dominant responses by the presence of an audience and the mere presence of others. Journal of Personality and Social Pscychology, n. 9, p. 245$250,1968$.

DEL REY, R; ORTEGA, R. La violencia escolar: estrategias de prevención. Barcelona, 2003.133p.

DOMINGUEZ, M.C.A. et al. Manual de atención al alumnado con necesidades específicas de apoyo educativo derivadas de trastornos graves de conducta. Sevilla: Junta de Andalucia, s.d.

ESTRELA, M. T. Relação pedagógica, disciplina e indisciplina na aula. 4 ed. Porto: Porto Editora, 1992.

FANTE, C. Fenômeno Bullying. Como prevenir a violência nas escolas e educar para a paz. 2 ed. Campinas, SP: Verus, 2005

FERREIRA, M. C. A Psicologia Social contemporânea: principais tendências e perspectivas nacionais e internacionais. Psicologia:Teoria e Pesquisa. Brasília, vol.26, p. 51-64, 2010.

FRANCISCO; M.V; LIBÓRIO; R.MC. Um estudo sobre bullying entre escolares do ensino fundamental. Psicologia Reflexão e Crítica. Porto Alegre, RS, vol.22, n.2, p. 200-207, 2009.

GOLDEN5 facebook. Disponível em: <http://www.facebook.com/pages/Golden5/183249155053579? fref=ts >. Acesso em 25 out. 2012.

GOLDEN5 youtube. Disponível em: <http://www.youtube.com/user/Golden5Project>. Acesso em 25 out. 2012. 
GOLDEN5, Palestine II Edition. Disponível em:<http://goldenoriente.blogspot.com. es/2012/10/la-cultura-como-fuente-de-libertad.html?spref=fb>. Acesso em 25 out. 2012.

GOMES, C. A.et al. A violência na ótica de alunos adolescentes do Distrito Federal. Cadernos de pesquisa. São Paulo, v. 36, n. 127, p. 11-34, jan./abr. 2006.

GOMES, C. A. A escola de qualidade para todos: abrindo as camadas da cebola. Ensaio: avaliação de políticas públicas em Educação. Rio de Janeiro, v. 13, n. 48, p. 281-306, jul./set. 2005.

GONÇALVES, L. A. O; SPOSITO, M. P. Iniciativas públicas de redução da violência escolar no Brasil. Cadernos de Pesquisa. São Paulo, n.115, p.101-138, mar. 2002.

GONÇALVES, L. A. O.; TOSTA, S. P. (Orgs.). A síndrome do medo contemporâneo e a violência na escola. Belo Horizonte: Autêntica, 2008.

HARTER, S. A new self report scale of intrinsec versus extrinsic orientation on the classroom: motivational and informational components. Development Psychology, v. 17, p. 300-312, 1981.

HEIDER, F. The psychology of interpersonal relations. New York: Wiley, 1958.

HERNANDEZ y HERNANDEZ, F; GIL, J.M.S. E1 clima escolar en los centros de secundaria: más alla de los tópicos. España: CIDE. Cientro de Investigación y Documentación Educativa. 2004.IPEA, Instituto de Pesquisa Econômica Aplicada. Educação no Brasil: atrasos, conquistas e desafios. In: ___ Brasil- o estado de uma nação: mercado de trabalho, emprego e informalidade. Rio de Janeiro: IPEA, p. 121-228, 2006.

LA TAILLE, Y.; PEDRO-SILVA, N.; JUSTO, J. S. Indisciplina: ética, moral e ação do professor. Porto Alegre: Mediação, 2006.

LERA, M. J. Claves psicológicas para entender laconvivencia escolar. s.d. Disponível em: <http://www.psicoeducacion.eu/node/2918>. Acesso em 20 jul. 2012.

LERA, M. J. et al. Inicio y fundamentos. In: LERA et alGolden5: una intervención psicoeducativa. Sevilla: Universidad de Sevilla, 2009. Disponível em: <www.golden5.org>Acesso em 25 out. 2012.

LERA, et al. Golden5. Results: impactevaluation. In: LERA, MariaJose et al. Golden5: una intervencion psicoeducativa. Sevilla: Universidad de Sevilla, 2009a. Disponívelem: <www.golden5.org.>Acesso em 25 out. 2012.

LERA, et al. PilotStudy. In: LERA, MariaJose et al. Golden5: una intervencion psicoeducativa. Sevilla: Universidad de Sevilla, 2009b. Disponível em: <www.golden5.org.>

LERA, M.J. Más allá de Europa: Golden5 en Palestina. In: LERA, et al.Golden5: una intervención psicoeducativa. Sevilla: Universidad de Sevilla, 2009c. Disponívelem:<www.golden5. org>Acessoem 25 out. 2012.

LERA, M. J. Competencias Golden.In: LERA, M. J. et al Golden5: una intervención psicoeducativa. Sevilla: Universidad de Sevilla, 2009d. Disponível em: <www.golden5.org >Acesso em 25 out. 2012.

MALTA, D. C. et al. Bullying nas escolas brasileiras: resultados da Pesquisa Nacional de Saúde do Escolar (PeNSE), 2009. Ciência e saúde coletiva, Rio de Janeiro, v. 15,s. 2, out. 2010.

MARQUÉS, J.G et al. BASC: sistema de evaluación de la conducta de niños y adolescentes. Madrid: Tea Ediciones, 2004.

MEAD,G.H. Mind, self and society. Chicago: University of Chicago Press, 1934.

MOYA, J. Evaluación externa del proyecto Golden5. 2007. In: LERA, M. J. (coord.) Golden5: una intervención psicoeducativa. Sevilla: Universidad de Sevilla, 2009. Disponívelem: <www. golden5.org> 
NEWCOMB, T.M. The acquaintance process. New York: Aolt, Rinehart \&Whiston, 1961.

PUPO, K. R.Violência moral no interior de uma escola: um estudo exploratório das representações do fenômeno sob a perspectiva de gênero. São Paulo: Dissertação apresentada à Faculdade de Educação da Universidade de São Paulo. 2007.

SPOSITO, M. P. Um breve balanço da pesquisa sobre violência escolar no Brasil. Educação e Pesquisa. São Paulo, v. 27, n. 1, p. 87-103, jun. 2001.

VASCONCELLOS, C. S. (In)Disciplina: construção da disciplina consciente e interativa em sala de aula e na escola. 16 a ed. São Paulo: Libertad Editora, 2006.

VIEIRA, T. M.; MENDES, F. D. C.; GUIMARÃES, L. C. De Columbine à Virgínia Tech: reflexões com base empírica sobre um fenômeno em expansão. Psicologia Reflexão e Crítica. Porto Alegre, RS, v. 22, n. 3, p. 493-501, 2009.

WENTZEL, K. Social goals and social relationships as motivators of school adjustment. In: JUNOVEN; WENTZEL. Social motivation: understanding children's school adjustment Cambridge: Cambridge University Press, 1996.

\section{Notas}

${ }^{1} \mathrm{O}$ Golden5 foi publicado como um livro digital que está disponível na internet no site www.golden5.org e permite-se o seu uso mencionando-se a fonte original e a página web de procedência. Toda a informação de www.golden5.org está sujeita a copyright.

${ }^{2}$ O Golden 5 foi aplicado na Espanha, Itália, Polônia, Noruega, Bélgica e em alguns territórios da Palestina.

${ }^{3}$ O Programa Golden5 foi financiado pelo Programa Socrates-Comenius que é mantido pela União Europeia para apoiar pesquisas sobre o ensino nas escolas e recebeu em março de 2009 um prêmio pela Comissão Europeia como um dos projetos Comenius mais exitosos. O projeto em si durou de 2004 a 2008 e se centrou no ensino secundário, mas atualmente vem expandindo sua atuação para outros níveis educativos e para além do contexto escolar, tendo em 2012, envolvido ONG'S e outras instituições educativas como centros de atendimento a adolescentes em situação de vulnerabilidade que oferecem atividades no contra turno escolar.

${ }^{4}$ Equipe que criou o Golden5: Maria Jose Lera (professora de Psicologia da Universidade de Sevilha, na Espanha); Knud Jensen e FrodeJosang (Professores de Educação Especial na RansvickSchool em Stavanger, Noruega); Joanna Szymanska (Psicóloga e coordenadora da Equipe de Prevenção psicológica do Centro Nacional de Formação de Professores - CentrumMetodcznePomocyPsychologiczno-Pedagogicznej de Varsóvia na Polônia); Elena Buccoliero (socióloga e professora do Centro de Promoção de Comunicações, em Ferrara, Itália) e JoelleTimmermans (mediadora e Professora do Le Souffle em Bruxelas, na Bélgica). Os autores do Projeto tinham em comum o fato de terem trabalhado juntos em projetos para a melhoria da convivência escolar.

${ }^{5}$ A Teoria da atribuição e do Equilíbrio fundamenta-se na "teoria da interação simbólica" de George H. Mead (1934).

${ }^{6}$ Para obter todos estes questionários, basta-se registrar no site: www.golden5.org.

${ }^{7}$ Como já foi dito anteriormente, o número 5 é uma referência. O professor pode aplicar somente 4 passos ou trabalhar 6 semanas, se considerar melhor. A sugestão do número 5 é para facilitar o trabalho do professor e para permitir que ele veja os seus resultados e tenha maior sistematicidade. Um passo chave aplicado 2 dias pode não ter resultados e um uso muito frequente também pode fazer com que perca a sua eficiência.

${ }^{8}$ Este material pode ser adquirido sem custos. Entrar em contato pelo e-mail:ritasouza@ufv.br 
${ }^{9}$ LERA, et al. Golden5. Results: impact evaluation. In: LERA, Maria Jose et al. Golden5: una intervencion psicoeducativa. Sevilla: Universidad de Sevilla, 2009. Disponível em: <www.golden5.org.>

10 LERA, et al. Pilot Study. In: In: LERA, Maria Jose et al. Golden5: una intervencion psicoeducativa. Sevilla: Universidad de Sevilla, 2009. Disponível em: <www.golden5.org.>

11 Em outubro de 2012 uma nova equipe composta por seis estudantes da Universidade de Sevilha foi à Palestina por dois meses visando trabalhar na continuidade do Programa Golden5.

12 LERA, M.J. Más allá de Europa: Golden5 en Palestina. In: LERA, Maria Jose et al. Golden5: una intervencion psicoeducativa. Sevilla: Universidad de Sevilla, 2009. Disponível em: <www.golden5.org.>

${ }^{13}$ Esta avaliação foi feita pelo Prof. Dr. José Moya do Grupo Atlantida, Professor da Universidade de Las Palmas em Gran Canárias, Espanha.

${ }_{14}$ Segundo Dominguez et al (s.d), o transtorno negativista desafiante (ou transtorno oposicionista desafiante) aparece sobretudo na primeira infância e o transtorno dissocial é característico da adolescência. $\mathrm{O}$ transtorno negativista desafiante se caracteriza por comportamentos desafiantes, negativos, irritabilidade em geral, em relação a adultos e/ou figuras de autoridade. $\mathrm{O}$ transtorno dissocial implica uma participação consciente dos adolescentes em atos que entram em conflito com a norma social e com os códigos de convivência.

${ }^{15}$ Os cursos de formação e o acompanhamento dos trabalhos foram financiados pela Prefeitura de Sevilla.

${ }_{16}$ Apresentação dos resultados do Golden5 para a Prefeitura de Sevilha (outubro de 2012) não publicado.

${ }_{17}$ O teste aplicado chama-se BASC e avalia a conduta de crianças e adolescentes. MARQUÉS, J.G et al. BASC: sistema de evaluación de la conducta de niños y adolescentes. Madrid: Tea Ediciones, 2004.

18 A primeira mensagem é de 10 de outubro de 2007 e a última de 04 de junho de 2012. A consulta foi feita em 17 de outubro de 2012.

* Professora Doutora da Universidade Federal de Viçosa, Vicosa, Minas Gerais - Brasil.

*** Professora Doutora da Universidade Federal de Viçosa, Vicosa, Minas Gerais - Brasil.

\section{Correspondência}

Rita de Cássia de Souza - Universidade Federal de Viçosa, Departamento de Educação. Av. P.H. Rolfs s/n Campus Universitário, CEP: 36570-000, Vicosa, Minas Gerais - Brasil.

E-mail: ritasouza@ufv.br-lera@us.es

Recebido em 26 de outubro de 2012

Aprovado em 23 de novembro de 2013 